\title{
Spectroscopic, Thermal Behaviour and DFT Calculations of a Trifluoromethyl Substituted Stilbene Imine Derivative as an Organic Semiconductive Material
}

\author{
Rafizah Rahamathullah ${ }^{1,2}$ and Wan M. Khairul ${ }^{*}$ \\ ${ }^{1}$ School of Fundamental Science, Universiti Malaysia Terengganu, \\ 21030 Kuala Nerus, Terengganu, Malaysia \\ ${ }^{2}$ Faculty of Engineering Technology, Universiti Malaysia Perlis, \\ Level 1, Block S2, UniCITI Alam Campus, Sungai Chuchuh, \\ 02100 Padang Besar, Perlis, Malaysia \\ *Corresponding author: wmkhairul@umt.edu.my
}

Published online: 25 February 2018

To cite this article: Rahamathullah, R. \& Khairul, W. M. (2018). Spectroscopic, thermal behaviour and DFT calculations of a trifluoromethyl substituted stilbene imine derivative as an organic semiconductive material. J. Phys. Sci., 29(Supp. 1), 83-89, https://doi. org/10.21315/jps2018.29.s1.11

To link to this article: https://doi.org/10.21315/jps2018.29.s1.11

\begin{abstract}
A new hybrid of stilbene imine derivative consisting of trifluoromethyl group as an active polar head group (acceptor, A) and hexyloxy tail chain as a donating component (donor, D) has been successfully synthesised as an organic semiconductive material. The compound, namely 4-[(hexyloxyphenyl)methylene]amino)-4'-trifluoromethylstilbene (HMTS) has been elucidated further for their physico-chemical properties via several selected spectroscopic and analytical methods, namely FTIR, UV-Vis, ${ }^{1} \mathrm{H}$ and ${ }^{13} \mathrm{C}$ $N M R$ and TGA. In addition, HMTS was evaluated theoretically via Gaussian 09 software which employs the density functional theory (DFT) approach with set of basis function B3LYP/6-31G (d,p). The quantum mechanical calculations proved that the value of energy separation between HOMO and LUMO of HMTS was $3.49 \mathrm{eV}$, which was in good agreement with the experimental value of optical band gap, $3.49 \mathrm{eV}$. From the preliminary result, a good relation between the experimental and theoretical data provided strong evidence that HMTS could be a potential material in organic semiconductor application, particularly with respect to their small HOMO-LUMO gap and high stability. According to the thermogravimetric studies, HMTS showed good thermal stability, without decomposition up to ca. $270^{\circ} \mathrm{C}$ and displayed remarkable performance under prolonged thermal stress.
\end{abstract}

Keywords: Stilbene imine, DFT calculation, organic semiconducting material, spectroscopic, trifluoromethyl 


\section{INTRODUCTION}

Research on organic semiconductor materials derived from polymeric and $\pi$-conjugated molecules plays a key component in the development of molecular electronic applications. ${ }^{1-3}$ The exploitation of organic semiconducting materials based on electron push and pull structures (also called donor-acceptor (D-A)) has been rapidly developed to finely tune the energy level and solubility of these materials so that they can perform function at an optimum level. ${ }^{4}$ These promising candidates also comprise of electronic delocalisation in extended $\pi$-orbital systems and contain a fair number of alternating single and double bonds, in which the electrons can flow from one reservoir to another that resulted in the effective properties of electrical conductivity. In these respects, the choice of materials with good thermal stability and low band gap energy of the corresponding materials to act as semiconductor materials is critical for the manufacture of stable and efficient organic electronics devices. ${ }^{5}$ Therefore, by insertion of $\pi$-conjugated moieties which possess electron donating and withdrawing groups in the molecule itself, the HOMO-LUMO energy gap of the molecules can be controlled and they become more efficient and active materials because the electrons can be generated in-situ in the conjugated system. With regard to this matter of high interest in developing single molecule organic semiconducting material, we herein report a new stilbene imine hybrid system, 4-[(hexyloxyphenyl)methylene]amino)-4'-trifluoromethylstilbene (HMTS) which consists of an active trifluoromethyl $\left(\mathrm{CF}_{3}\right)$ group at one end, and hexyloxy chain at the other as shown in Figure 1.

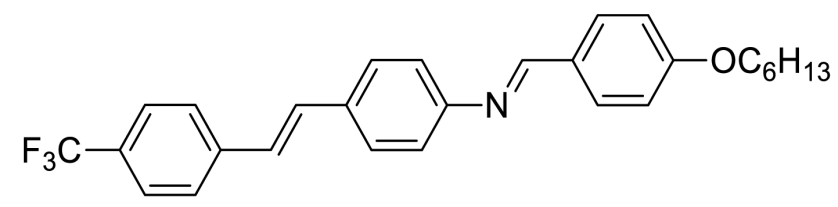

Figure 1: Molecular structure of HMTS.

\section{EXPERIMENTAL}

\subsection{Materials}

All chemicals and materials were commercially purchased from standard commercial suppliers and used as received without further purification. The reactions were carried out under an ambient atmosphere and no special steps were taken to exclude moisture during experimental work-up. The infrared (IR) spectrum was recorded on Perkin Elmer Spectrum 100 Fourier transform infrared spectrometer in the form of potassium bromide $(\mathrm{KBr})$ pellets in the spectral range 
of 4000-400 $\mathrm{cm}^{-1}$. The UV-Vis spectrum was recorded using Shidmadzu UV-1800 $\mathrm{UV}-\mathrm{Vis}$ spectrophotometer in a $1-\mathrm{cm}$ path length quartz cell in dichloromethane at a concentration of $1 \times 10^{-5} \mathrm{M}$ in the spectral range of 200-500 nm. NMR spectra were recorded on Bruker Avance III 400 Spectrometer ${ }^{1} \mathrm{H}(400.11 \mathrm{MHz})$ and ${ }^{13} \mathrm{C}(100.61 \mathrm{MHz})$ using deuterated chloroform $\left(\mathrm{CDCl}_{3}\right)$ as solvent and TMS an internal standard. Thermogravimetric analysis was performed using Perkin-Elmer TGA Analyzer from $30^{\circ} \mathrm{C}$ to $900^{\circ} \mathrm{C}$ at a heating rate of $10^{\circ} \mathrm{C} \mathrm{min}{ }^{-1}$ under nitrogen atmosphere.

\subsection{Synthesis}

The synthesis of HMTS comprised of three steps: the syntheses of 4-hexyloxybenzaldehyde (1) and a Heck cross-coupling protocol derivative, 4-amino-4'-trifluoromethyl stilbene (2) as precursor; and HMTS via a Schiff base reaction. However, the experimental details of the synthesis of 1 have been reported in literature. ${ }^{6}$ The preparation of HMTS is summarised in Scheme 1. A two-neck 50-ml round bottom flask containing equimolar amounts of 1 $(0.3 \mathrm{~g}, 1.45 \mathrm{mmol})$ and $2(0.38 \mathrm{~g}, 1.45 \mathrm{mmol})$ in ethanolic solution was fitted with a Dean-stark condenser. Then, the mixture was put at reflux with constant stirring for $c a$. $6 \mathrm{~h}$ and reaction progress was monitored using TLC (hexane: ethyl acetate) (4:1). Once the reaction was completed, the solvent was removed in vacuo and the crude product was recrystallised from acetonitrile to afford the yellow precipitate of the titled compound, HMTS $(0.51 \mathrm{~g}, 78 \%$ yield).

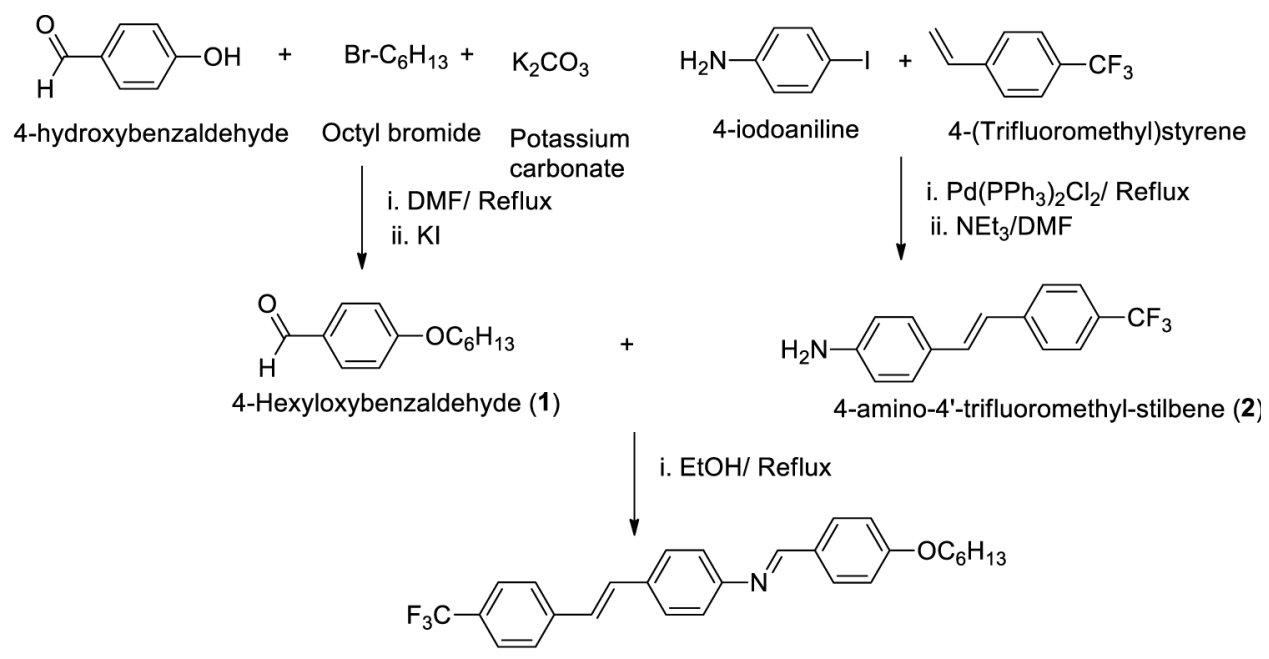

4-[(hexyloxyphenyl)methylene]amino)-4'-trifluoromethyl-stilbene (HMTS)

Scheme 1: The synthesis pathway for the preparation of HMTS. 
IR (KBr): $v\left(\mathrm{C}-\mathrm{H}\right.$ aromatic) $3445 \mathrm{~cm}^{-1}, v\left(\mathrm{C}-\mathrm{H}\right.$ aliphatic) $2934 \mathrm{~cm}^{-1}, 2874 \mathrm{~cm}^{-1}$, $v(\mathrm{C}=\mathrm{C}) 1585 \mathrm{~cm}^{-1}$ and $1566 \mathrm{~cm}^{-1}, v(\mathrm{C}=\mathrm{N}) 1624 \mathrm{~cm}^{-1}, v(\mathrm{C}-\mathrm{O}) 1326 \mathrm{~cm}^{-1} .{ }^{1} \mathrm{H}$ NMR $\left(\mathrm{CDCl}_{3}\right): \delta 0.92\left(\mathrm{t}, J=7 \mathrm{~Hz}, 3 \mathrm{H}, \mathrm{CH}_{3}\right) ; 1.26-1.85\left(\mathrm{~m}, 8 \mathrm{H}, \mathrm{CH}_{2}\right) ; 4.03(\mathrm{t}, J=7 \mathrm{~Hz}, 2 \mathrm{H}$, $\mathrm{OCH}_{2}$ ); 6.97 (pseudo-d, $J_{\mathrm{HH}}=9 \mathrm{~Hz}, 2 \mathrm{H}, \mathrm{C}_{6} \mathrm{H}_{4}$ ); 7.26 (pseudo-d, $J_{\mathrm{HH}}=8 \mathrm{~Hz}, 2 \mathrm{H}, \mathrm{C}_{6} \mathrm{H}_{4}$ ); 7.55 (pseudo-d, $\left.J_{\mathrm{HH}}=6 \mathrm{~Hz}, 2 \mathrm{H}, \mathrm{C}_{6} \mathrm{H}_{4}\right) ; 7.60\left(\mathrm{~s}, 4 \mathrm{H}, \mathrm{C}_{6} \mathrm{H}_{4}\right) ; 7.84$ (pseudo-d, $J_{\mathrm{HH}}=9 \mathrm{~Hz}$, $\left.2 \mathrm{H}, \mathrm{C}_{6} \mathrm{H}_{4}\right) ; 7.08-7.22\left(\mathrm{~d}-\mathrm{d}, 2 \mathrm{H}, \mathrm{C}_{2} \mathrm{H}_{4}\right) ; 8.42(\mathrm{~s}, 1 \mathrm{H}, \mathrm{NH}) .{ }^{13} \mathrm{C} \mathrm{NMR}\left(\mathrm{CDCl}_{3}\right): \delta$ $13.00\left(\mathrm{~s}, \mathrm{CH}_{3}\right) ; 21.58,24.67,28.13,30.55,\left(4 \times \mathrm{s}, \mathrm{CH}_{2}\right) ; 67.24(\mathrm{~s}, \mathrm{C}-\mathrm{O}) ; 127.94$, $129.58(2 \times \mathrm{s}, \mathrm{C}=\mathrm{C}) ; 113.74,120.44,124.60,124.63,125.35,125.46,126.63$, $129.75,133.08,151.29,158.69,160.00(12 \times \mathrm{s}, \mathrm{Ar}) ; 161.03(\mathrm{~s}, \mathrm{C}=\mathrm{N})$.

\section{RESULTS AND DISCUSSION}

\subsection{Spectroscopic Studies}

The IR spectrum of HMTS revealed all the expected bands of interest, namely $v(\mathrm{C}-\mathrm{H}), v(\mathrm{C}=\mathrm{C}$ alkene $), v(\mathrm{C}=\mathrm{C}$ aromatic $)$ and $v(\mathrm{C}=\mathrm{N})$. The bands from $2874 \mathrm{~cm}^{-1}$ to $2934 \mathrm{~cm}^{-1}$ corresponded to $\mathrm{C}-\mathrm{H}$ stretching of the alkyl substituent. The absorption band for $v(\mathrm{C}=\mathrm{C})$ alkene and aromatic stretching vibration occurred at low frequencies, $1585 \mathrm{~cm}^{-1}$ and $1566 \mathrm{~cm}^{-1}$, respectively with moderate intensity. This is due to the effect of phenyl ring which is strongly coupled with the $v(C=C)$ stretching of the vinyl bond and $v(\mathrm{C}-\mathrm{F})$ of the acceptor. ${ }^{7}$ The presence of $v(\mathrm{C}=\mathrm{N})$ stretching vibration could be observed at a low frequency, $1624 \mathrm{~cm}^{-1}$ which is an indication of a Schiff base formation and this value is in good agreement with previously studied systems. ${ }^{8}$ The ${ }^{1} \mathrm{H}$ NMR spectrum for HMTS showed resonance of the methyl protons at $\delta_{\mathrm{H}} 0.88 \mathrm{ppm}$ while that of methylene protons were observed in the range of $\delta_{\mathrm{H}} 1.25-1.83 \mathrm{ppm}$. R-O- $\mathrm{CH}_{2}$ - signal of the methoxy protons was detected downfield, at $\delta_{\mathrm{H}} 4.05 \mathrm{ppm}$ because they were deshielded due to their close proximity to the electron withdrawing oxygen atom. Whilst, the aromatic protons could be observed around $\delta_{\mathrm{H}} 6.90-7.79 \mathrm{ppm}$ as multiplets. The disappearance of amine and aldehyde protons and the presence of azomethine proton $(\mathrm{CH}=\mathrm{N})$ at $\delta_{\mathrm{H}}$ $8.35 \mathrm{ppm}$ confirmed the occurrence of condensation reaction between amine and aldehyde to produce the targeted compounds, HMTS. The carbon peaks in the ${ }^{13} \mathrm{C}$ NMR spectrum of HMTS was consistent with those in the proposed molecular structure of this compound. The methyl carbon resonance could be clearly observed at $\delta_{\mathrm{C}} 14.03 \mathrm{ppm}$ and carbon resonances in the alkyl chain were detected in the range of $\delta_{\mathrm{C}} 22.60-31.58 \mathrm{ppm}$, which were in good agreement with those of the previous reports on similar systems. Whilst, the downfield-shift resonance of the oxygenated carbon could be found at $\delta_{\mathrm{C}} 62.69 \mathrm{ppm}$ due to deshielding effect of oxygen atom that withdraws electron density from the former. Meanwhile, the resonances for aromatic carbons were seen in the range of $\delta_{\mathrm{C}} 113.73$ to $158.56 \mathrm{ppm}$. Signal of the imine carbons, $\mathrm{C}=\mathrm{N}$ was observed at $\delta_{\mathrm{C}} 160.82 \mathrm{ppm}$. 
HMTS exhibited good thermal stability up to $c a .270^{\circ} \mathrm{C}$. Its thermogram revealed no mass loss occurred below $100^{\circ} \mathrm{C}$ which indicated that there was no trace of water or solvent in the sample. The degradation process of HMTS started at $290^{\circ} \mathrm{C}\left(T_{\text {onset }}\right)$ and ended around $400^{\circ} \mathrm{C}\left(T_{\text {offset }}\right)$ which was higher than that of its precursor. Whilst, the second stage started at $410^{\circ} \mathrm{C}\left(T_{\text {onset }}\right)$ and ended at $850^{\circ} \mathrm{C}\left(T_{\text {offset }}\right)$. Thus, the targeted compound was thermally stable, even at high temperature, an indication of the good potential of this compound be applied as a semiconductive film for it had remarkable performance under prolonged thermal stress.

\subsection{Optical Properties}

The electronic transition spectrum of HMTS showed broad absorption bands at $\lambda_{\max } 356 \mathrm{~nm}$ which could be attributed to $\pi \rightarrow \pi^{*}$ and $n \rightarrow \pi^{*}$ transitions of the phenyl, $\mathrm{C}=\mathrm{C}$ alkene and $\mathrm{C}=\mathrm{N}$ moieties. The energy band gap $\left(E_{\mathrm{g}}\right)$ was calculated using Equation 1 which was expressed in $\mathrm{eV} .{ }^{6}$ According to the UV-vis spectrum of HMTS, the absorption maximum $\left(\lambda_{\text {abs } \cdot \max }\right)$ was found to be at $356 \mathrm{~nm}$ which led to experimental optical energy band gap of $3.49 \mathrm{eV}$.

$$
E_{\mathrm{g}}(\mathrm{eV})=\frac{1240}{\lambda_{\text {abs.max }}}
$$

The molecular geometry of HMTS was optimised via the density functional theory (DFT) calculations to investigate the energy separation between the HOMO and LUMO as depicted in Figure 2.

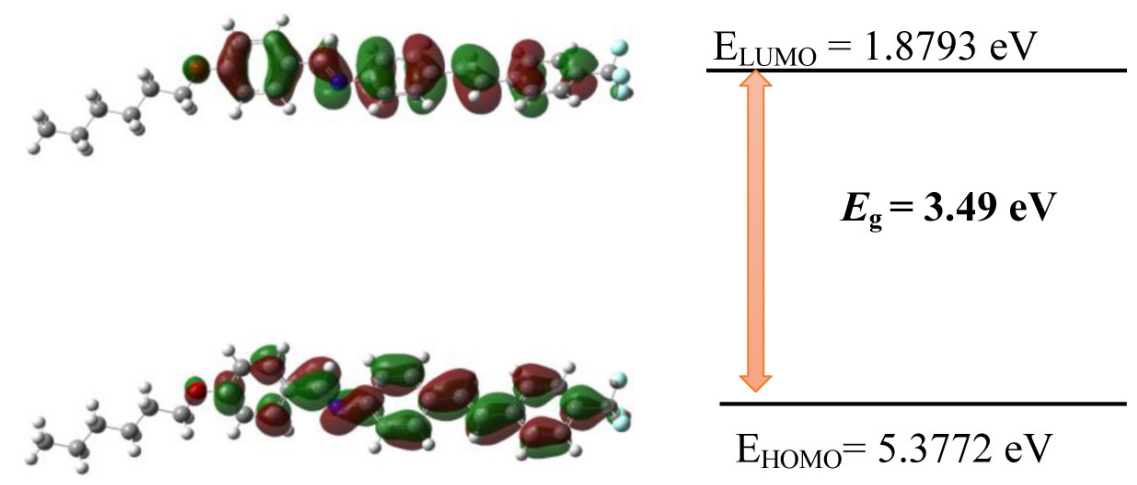

Figure 2: Energy gap between HOMO and LUMO of HMTS.

From the data analysis, it was clearly observed that the theoretical energy band gap value, $3.49 \mathrm{eV}$ was in good agreement with the experimental optical band gap, 3.49 $\mathrm{eV}$ obtained from UV-Vis absorption spectroscopy. Notably, the electron cloud of 
the HOMO in HMTS is mainly located on the electron withdrawing trifluromethyl substituent, whereas the LUMO is dominated by orbitals from the stilbene aromatic system. Generally, such electron distribution imparts to the investigated molecule an intrinsic intramolecular charge transfer property, which is consistent with the experimental spectroscopic data. In addition, this minimal overlapping of HOMO-LUMO also afforded HMTS with smaller energy for photo-excitation and relaxation, thus its theoretical band gap energy $\left(E_{\mathrm{g}}\right)$ was calculated as $3.49 \mathrm{eV}$ which lies in the typical band gap range of organic semiconducting materials.

\section{CONCLUSION}

HMTS featuring donor (D)- $\pi$-acceptor (A) properties has been successfully synthesised with good yield $(75 \%)$. The optical band gap of this derivative exhibited is $3.49 \mathrm{eV}$, which showed good relationship between the experimental and theoretical data. Indeed, the material possesses good thermal stability at high temperature up to $c a \cdot 270^{\circ} \mathrm{C}$. Thus, the findings showed that the targeted molecule can be a material candidate to be used candidate in organic semiconductor application.

\section{ACKNOWLEDGEMENTS}

The authors would like to acknowledge the Ministry of Higher Education (MOHE) Malaysia for financial support through research grant FRGS and SLAB Scholarship from Universiti Malaysia Perlis; School of Fundamental Science, Universiti Malaysia Terengganu is acknowledged for providing specific facilities and research aid.

\section{REFERENCES}

1. Günes, S., Neugebauer, H. \& Sariciftci, N. S. (2007). Conjugated polymerbased organic solar cells. Chem. Rev., 107(4), 1324-1338, https://doi. org/10.1021/cr050149z.

2. Beaujuge, P. M. \& Fréchet, J. M. (2011). Molecular design and ordering effects in $\pi$-functional materials for transistor and solar cell applications. $J$. Am. Chem. Soc., 133(50), 20009-20029, https://doi.org/10.1021/ja2073643.

3. Jiang, W., Li, Y. \& Wang, Z. (2013). Heteroarenes as high performance organic semiconductors. Chem. Soc. Rev., 42(14), 6113-6127, https://doi. org/10.1039/c3cs60108k. 
4. Steim, R., Kogler, F. R. \& Brabec, C. J. (2010). Interface materials for organic solar cells. J. Mater. Chem., 20(13), 2499-2512, https://doi.org/10.1039/ b921624c.

5. Costa, J. C. et al. (2016). Optical band gaps of organic semiconductor materials. Opt. Mater., 58, 51-60, https://doi.org/10.1016/j.optmat.2016. 03.041 .

6. Williamson, A. W. (1852). On etherification. J. Chem. Soc., 4, 229-234.

7. Delgado, M. R. et al. (2004). Quantum chemical DFT and spectroscopic study of a push-pull chromophore for second-order nonlinear optics containing bithiophene as the electron relay. J. Mol. Struct. THEOCHEM., 709(1), 187-193, https://doi.org/10.1016/j.theochem.2003.10.082.

8. Sek, D. et al. (2012). New glass forming triarylamine based azomethines as a hole transport materials: Thermal, optical and electrochemical properties. Opt. Mater., 34, 1333-1346, https://doi.org/10.1016/j.optmat.2012.02.014. 